\title{
Response of Lipids and Lipoproteins to Regular Aquatic Endurance Exercise: A Meta-Analysis of Randomized Controlled Trials
}

\author{
Yutaka Igarashi ${ }^{1}$ and Yoshie Nogami ${ }^{2}$
}

${ }^{1}$ Graduate School of Sport and Exercise Sciences, Osaka University of Health and Sport Sciences, Osaka, Japan

${ }^{2}$ Faculty of Engineering, Department of Human Environmental Sciences, Shonan Institute of Technology, Kanagawa, Japan

Aim: No meta-analysis has examined the effect of regular aquatic endurance exercise on lipid and lipoprotein levels. The purpose of the current work was to perform a meta-analysis to evaluate the effects of regular aquatic endurance exercise on lipid and lipoprotein levels.

Methods: The inclusion criteria of the randomized controlled trials were healthy adults in an exercise group performing regular aquatic exercise and a control group not exercising, with a description of the serum high-density lipoprotein cholesterol (HDL-C), low-density lipoprotein cholesterol (LDL-C), total cholesterol, or triglyceride levels provided. The net change in the lipid and lipoprotein levels was calculated from each trial, and the changes in the lipid and lipoprotein levels were pooled using a random effects model.

Results: The meta-analysis examined 10 trials involving aquatic endurance exercise and 327 subjects. The pooled net changes in HDL-C, LDL-C, and total cholesterol improved significantly (HDL-C, $4.6 \mathrm{mg} / \mathrm{dL}$; LDLC, $-10.1 \mathrm{mg} / \mathrm{dL}$; total cholesterol, $-8.5 \mathrm{mg} / \mathrm{dL}$ ). When trials were limited to those involving only women, the pooled net changes in HDL-C, LDL-C, and total cholesterol improved significantly. When trials were limited to those involving subjects with a mean age $<60$ years, the pooled net changes in HDL-C, total cholesterol, and triglyceride improved significantly. When trials were limited to those with dyslipidemia, the pooled net changes in HDL-C, LDL-C, total cholesterol, and triglyceride improved significantly.

Conclusions: Aquatic endurance exercise improved the lipid and lipoprotein levels and benefited women, middle-aged subjects, and patients with dyslipidemia in particular.

Key words: Aquatic exercise, Lipids and lipoproteins, Meta-analysis

\section{Introduction}

Dyslipidemia is a major risk factor for cardiovascular disease. Several cohort studies have reported that adults with low levels of high-density lipoprotein cholesterol (HDL-C) or extremely high levels of HDL-C had a high risk of cardiovascular disease and a high mortality rate regardless of cause ${ }^{1-3)}$. In addition, lowdensity lipoprotein cholesterol (LDL-C) was strongly associated with cardiovascular disease or mortality when LDL-C was $\geq 190 \mathrm{mg} / \mathrm{dL}^{2,3)}$. The major risk factors for dyslipidemia are known to depend heavily on lifestyle, and several meta-analyses have indicated that lifestyle modifications improve the lipid and lipoprotein lev- $\mathrm{els}^{4-16)}$. Exercise is one way of improving these levels, and a number of studies have noted the beneficial effects of regular exercise on the lipid and lipoprotein levels. Metaanalyses of studies involving exercise have mainly examined the effects of endurance exercise ${ }^{10-13)}$ and resistance training ${ }^{14)}$, but recent analyses have examined the effects of other forms of exercise such as tai chi $^{15)}$ and yoga ${ }^{16}$ to promote health.

Aquatic exercise is a type of exercise that has recently increased in popularity ${ }^{17)}$ and involves characteristics specific to water, such as water temperature, resistance, hydrostatic pressure, buoyancy, and viscosity; as such, the physiological properties of aquatic exercise differ from those of land-based exercise. For ex-

Address for correspondence: Yutaka Igarashi, Graduate School of Sport and Exercise Sciences, Osaka University of Health and Sport Sciences, 1-1 Asashirodai, Kumatori-cho, Sennan-gun, Osaka 590-0496, Japan E-mail: yu_igarashi_000@mail.goo.ne.jp

Received: November 9, 2017 Accepted for publication: March 27, 2018

Copyright@2019 Japan Atherosclerosis Society

This article is distributed under the terms of the latest version of CC BY-NC-SA defined by the Creative Commons Attribution License. 
ample, aquatic exercise poses less of a physical burden when stationary or when moving at a low or moderate speed $^{18)}$. Therefore, aquatic exercise can be effective as a form of exercise therapy for patients with obesity or orthopedic disease. Previous meta-analyses have suggested that aquatic exercise exerts a beneficial effect on health by lowering blood pressure ${ }^{19)}$ and alleviating knee pain $^{20)}$, but no meta-analysis has examined the effects of regular aquatic exercise on the lipid and lipoprotein levels. In addition, land-based exercise and aquatic exercise result in similar levels of energy expenditure in metabolic equivalents, according to the guidelines of the American College of Sports Medicine ${ }^{21)}$. This suggests that aquatic exercise may be as effective as landbased exercise in terms of improving the lipid and lipoprotein levels. On the basis of this hypothesis, the purpose of the current work was to perform a metaanalysis to evaluate the effects of regular aquatic exercise on the lipid and lipoprotein levels.

\section{Methods}

A meta-analysis was performed in accordance with the Preferred Reporting Items for Systematic Reviews and Meta-analyses (PRISMA) statement ${ }^{22}$ and was registered in the International Prospective Register of Systematic Reviews (PROSPERO: https://www.crd.york. ac.uk/PROSPERO, registration number: CRD42017 075556).

\section{Data Sources and Study Selection}

Databases were searched for literature published until October 2017. MEDLINE, PubMed, SPORTDiscus, the Cochrane library, and Google Scholar were searched using terms such as dyslipidemia, hyperlipidemia, lipid, lipoprotein, cholesterol, exercise, exercise therapy, physical fitness, swimming, water, aquatic exercise, and water-based exercise. The literature was comprehensively searched using different combinations of these terms. Listed references of original articles, reviews, and textbooks were also searched. The inclusion criteria for this meta-analysis were as follows: subjects had no cardiovascular or other diseases with a mean age of 20 years or older; subjects were randomly divided into an aquatic exercise group and a control group (i.e., a randomized controlled trial), with the aquatic exercise group only performing regular exercise in water and the control group not exercising, and neither group receiving intervention such as an improved diet or a change in lifestyle; the intervention lasted four weeks or longer (based on previous meta-analyses ${ }^{8,9,14,15,19,23)}$ ); and studies described the mean HDL-C, LDL-C, total cholesterol (TC), or triglyceride (TG) levels and their standard deviation (SD) in the exercise and control groups before and after the intervention. Studies identified from a literature search were limited to those involving aquatic exercise and those examining the effect of this exercise on the lipid and lipoprotein levels. Once these studies were identified, two authors (Y.I. and Y.N) determined whether or not the study should be included in this meta-analysis.

\section{Data Extraction}

The data and details of the intervention (mean HDL-C, LDL-C, TC or TG, and SD in the serum lipids and lipoproteins, number of subjects, type of aquatic exercise, intensity, time, frequency, details of the control group, and duration of the intervention) were extracted from studies for the meta-analysis. Some serum lipid and lipoprotein data were converted from $\mathrm{mmol} / \mathrm{L}$ to $\mathrm{mg} / \mathrm{dL}$ cholesterol by multiplying the values by 38.7, and TG values were multiplied by 88.7 . The body mass index (BMI) was selected as a secondary outcome.

The study quality was assessed based on the Physiotherapy Evidence Database (PEDro) ${ }^{24)}$, with 10 terms scored at 1 point each. However, 2 points of the usual PEDro score depend on how a study is blind of subjects in groups and blind of therapists. In general, blinding of subjects is difficult in studies of exercise interventions ${ }^{23)}$. These 2 points were therefore excluded in this meta-analysis, and PEDro was assessed based on eight terms scored at 1 point each.

The two authors independently extracted and checked the aforementioned data and assessed the quality of the studies using the modified PEDro score.

\section{Statistical Analyses}

The net change in HDL-C, LDL-C, TC, TG, and BMI was examined for each trial. The change was defined as the difference (values for the exercise group minus values for the control group) in changes (final values minus baseline values) in the mean. Pooled net changes were calculated with a random-effects model using the DerSimonian-Laird method and weighted by the inverse variance of differences from the baseline to the final assessment in each trial ${ }^{25}$. The correlation coefficient between the baseline and the final assessment was assumed to be $0.50^{26)}$.

Cochran Q statistics were calculated, and the heterogeneity of pooled net change was examined among trials. The $\mathrm{I}^{2}$ statistic was calculated using the formula $(\mathrm{Q}-\mathrm{df}) / \mathrm{Q}$, where $\mathrm{df}$ is the degree of freedom (obtained by subtracting 1 from the number of trials). The level of heterogeneity was assessed using the $\mathrm{I}^{2}$ statistic: low risk (less than $25 \%$ ), moderate risk ( $25 \%$ to $75 \%$ ), and high risk (greater than $75 \%)^{27)}$.

Subgroup analyses of pooled net changes in the 


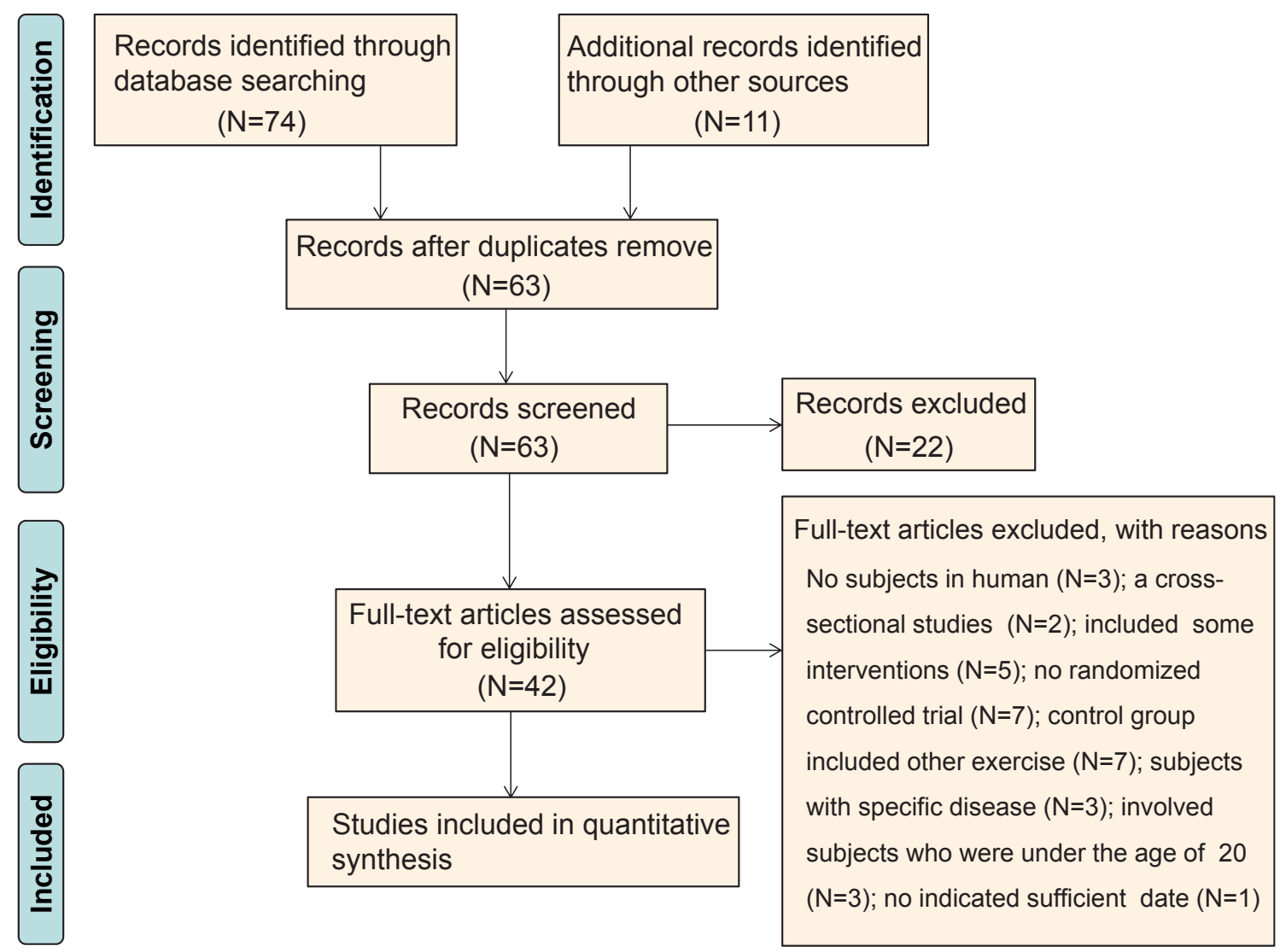

Fig. 1. PRISMA flow diagram regarding article selection for meta-analysis.

HDL-C, LDL-C, TC, and TG levels regarding the type of aquatic exercise were performed by classifying trials into endurance exercise, no endurance exercise, swimming, and no swimming. In addition, trials were limited to aquatic endurance exercise, and subgroup analyses were performed for eight categories: women only, women and men, mean age ( $\geq 60$ years and $<60$ years), intervention duration ( $\geq 8$ weeks and $\geq 12$ weeks), dyslipidemia, and no dyslipidemia. On the basis of the American Heart Association and the American College of Sports Medicine guidelines on physical activity to maintain health ${ }^{28)}$, endurance exercise was defined as exercise that was moderate to vigorous in activity and that lasted a minimum of 30 min per session. "Dyslipidemia" was defined based on the Japan Atherosclerosis Society guidelines ${ }^{29)}$, and trials with a mean HDL-C $<40 \mathrm{mg} / \mathrm{dL}$, mean LDL-C $\geq 140 \mathrm{mg} / \mathrm{dL}$, or mean TG $\geq 150 \mathrm{mg} / \mathrm{dL}$ of subjects were designated as having dyslipidemic subjects.

Two methods were used to evaluate any publication bias, i.e. the symmetry of funnel plots produced by the net changes in serum lipids or lipoproteins ( $\mathrm{x}$-axis) and the inverse of the standard error (y-axis) were assessed. First, the trim and fill method of Duval and
Tweedie was used to estimate the number of missing trials $^{30)}$. If the results suggested that trials were missing, then pooled net changes in lipids and lipoproteins were adjusted in light of the effect of these trials. Second, Egger's regression test was used to evaluate the asymmetry of funnel plots ${ }^{31)}$.

The results for baseline variables were expressed as the mean $\pm S D$ weighted by the number of subjects, and comparisons of the exercise group and control group were carried out by the Mann-Whitney test. In all the statistical tests, a $P$ value $<0.05$ was considered to be statistically significant. The results of net changes were expressed as the $95 \%$ confidence intervals (CI). The Comprehensive Meta-Analysis soft program (Version 2.2; Biostat, Inc., Englewood, NJ, USA) was used to perform the meta-analysis and assess the publication bias. Other statistical tests were performed using the SPSS soft program (Version 21.0; IBM Inc., Armonk, NY, USA).

\section{Results}

\section{Study Selection}

As a result of a literature search, 42 studies were 


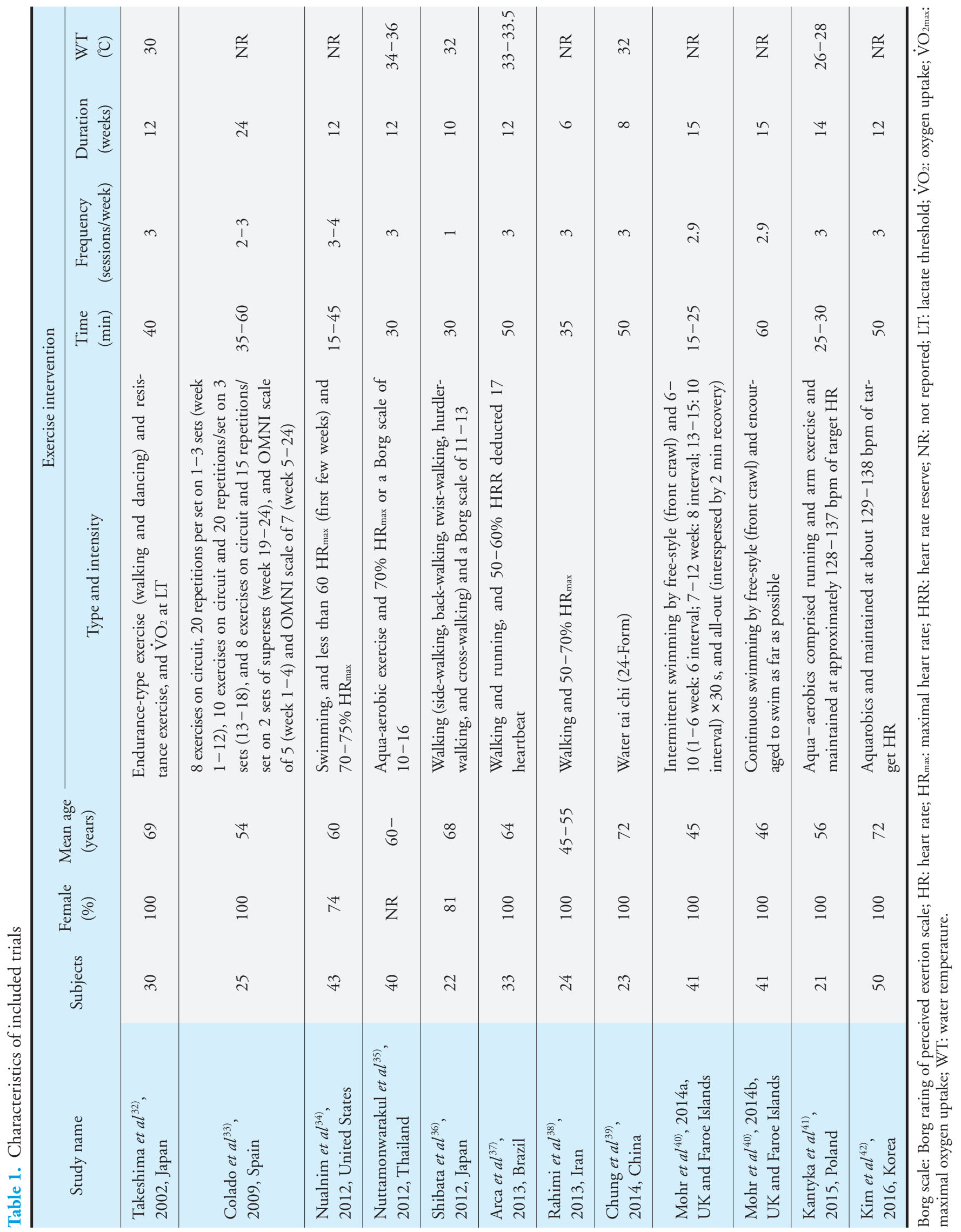


HDL-C $(\mathrm{mg} / \mathrm{dL})$

\begin{tabular}{|c|c|c|c|c|c|c|c|c|}
\hline Source & $\mathbf{n}$ & Baseline & Net change $(95 \% \mathrm{Cl})$ & & & & & \\
\hline \multicolumn{9}{|l|}{ Endurance exercise $(\mathrm{N}=9)$} \\
\hline Takeshima et al ${ }^{32)}, 2002$ & 30 & $64.9 \pm 13.4$ & $-1.0(-12.8$ to 10.8$)$ & & & & & \\
\hline Nualnim et $a^{34)}, 2012$ & 43 & $55.2 \pm 12.5$ & $4.0(-7.9$ to 15.9$)$ & & & & & \\
\hline Shibata et $a^{36)}, 2012$ & 22 & $68.9 \pm 11.4$ & $-1.3(-13.0$ to 10.4$)$ & & & & & \\
\hline Arca et $a l^{37)}, 2013$ & 33 & $50.8 \pm 8.7$ & $2.0(-6.9$ to 10.9$)$ & & & & & \\
\hline Rahimi et $a l^{38)}, 2013$ & 24 & $33.2 \pm 4.3$ & $9.8(3.9$ to 15.7$)$ & & & & & \\
\hline Chung et al ${ }^{39)}, 2014$ & 23 & $49.4 \pm 13.0$ & $-8.1(-20.9$ to 4.7$)$ & & & & & \\
\hline Mohr et al ${ }^{40)}, 2014 \mathrm{~b}$ & 41 & $54.2 \pm 13.1$ & $7.8(-2.9$ to 18.5$)$ & & & & & \\
\hline Kantyka et al ${ }^{41)}, 2015$ & 21 & $65.8 \pm 12.1$ & $3.6(-8.1$ to 15.3$)$ & & & & & \\
\hline Kim et $a^{42)}, 2016$ & 50 & $33.9 \pm 9.8$ & 9.4 (3.0 to 15.9$)$ & & & & & \\
\hline Pooled & 287 & $51.4 \pm 11.3$ & $4.6(0.8$ to 8.3$)$ & & & & & \\
\hline Heterogeneity & & & $Q=11.2, P=0.19 ; I^{2}=28.4 \%$ & -30.0 & -15.0 & 0.0 & 15.0 & 30.0 \\
\hline \multicolumn{9}{|c|}{ No endurance exercise $(\mathrm{N}=2)$} \\
\hline Colado et $a l^{33)}, 2009$ & 25 & $69.0 \pm 10.8$ & $-7.6(-17.2$ to 2.0$)$ & & & & & \\
\hline Mohr et al ${ }^{40)}, 2014 a$ & 41 & $54.2 \pm 13.1$ & $3.9(-6.8$ to 14.6$)$ & & & & & \\
\hline Pooled & 66 & $59.8 \pm 12.3$ & $-2.1(-13.4$ to 9.2$)$ & & & & & \\
\hline Heterogeneity & & & $Q=2.4, P=0.12 ; I^{2}=59.1 \%$ & -30.0 & -15.0 & 0.0 & 15.0 & 30.0 \\
\hline \multicolumn{9}{|l|}{ All of the trials $(\mathrm{N}=11)$} \\
\hline Pooled & 353 & $59.2 \pm 11.5$ & $3.1(-0.8$ to 6.9$)$ & & & & & \\
\hline Heterogeneity & & & $Q=19.3, P=0.02 ; I^{2}=45.1 \%$ & -30.0 & -15.0 & 0.0 & 15.0 & 30.0 \\
\hline
\end{tabular}

Fig. 2. Baseline HDL-C and forest plot for the net changes in HDL-C. Each trial is represented with black squares (net change) and widths $(95 \% \mathrm{CI})$; the size of the black squares is in proportion to the weighting by inverse variance in each trial. The pooled net changes are represented by black rhombuses (net change) and widths (95\% CI).

identified as involving aquatic exercise and describing lipid or lipoprotein data. Of these, 31 studies did not meet the selection criteria and were excluded from the meta-analysis (Fig. 1). As a result, 12 trials in 11 articles $\left(1\right.$ article included 2 trials ${ }^{32-42)}$ were ultimately analyzed.

\section{Trial Characteristics}

All trials had a parallel design and were in English. Table 1 shows the characteristics of each included trial. The trials involved 393 subjects in total: 208 subjects in the exercise groups and 185 subjects in the control groups. Eleven trials ${ }^{32-34,36-42)}$ reported the number of subjects by sex. These trials involved 16 males $(4.5 \%)$ and 337 females (95.5\%). Ten trials ${ }^{32-34,36,37,39-42)}$ reported the mean age of subjects, which ranged from 46 to 73 years (median: 62 years). Ten trials ${ }^{32,34-39,41,42)}$ carried out endurance exercise, one trial carried out endurance exercise plus resistance training ${ }^{33)}$, and one trial carried out exercise under $30 \mathrm{~min}^{40)}$. Three trials ${ }^{34,40)}$ carried out only swimming. Five trials $s^{34,35,38,41,42)}$ used the heart rate to gauge the intensity of exercise. All trials involved a set exercise time and frequency. An exercise session ranged from 15 to $60 \mathrm{~min}$. The frequency of exercise was $1-4$ sessions per week. The water tem- perature ranged from 26 to $36^{\circ} \mathrm{C}$ according to the six trials ${ }^{32,35-37,39,41)}$ that reported the temperature. The duration of intervention ranged from 6 to 24 weeks (median: 12 weeks). Supplementary Table 1 shows the PEDro on each trial, and the score ranged from 3 to 7 points (median: 5 points).

\section{Net Changes and Subgroup Analysis}

Figs. 2-5 show the results of baseline and forest plots of net changes in lipids and lipoproteins from each trial and the pooled net changes in lipids and lipoproteins. The pooled net changes in HDL-C, LDL-C, and TC in the trials of aquatic endurance exercise decreased significantly. The figures include the baseline HDL-C, LDL-C, TC, and TG levels and net changes in these levels according to trials not involving aquatic endurance exercise, and the pooled net changes did not improve significantly. The pooled net changes in LDL$\mathrm{C}$ and TC decreased significantly in all the trials. In addition, the pooled net changes in HDL-C, LDL-C, TC, and TG did not improve significantly in trials involving swimming ${ }^{34,40)}$, and the pooled net changes in LDL-C and TC improved significantly in trials not involving swimming (Supplementary Table 2) ${ }^{32,33,35-39,41,42) .}$ 
LDL-C (mg/dL)

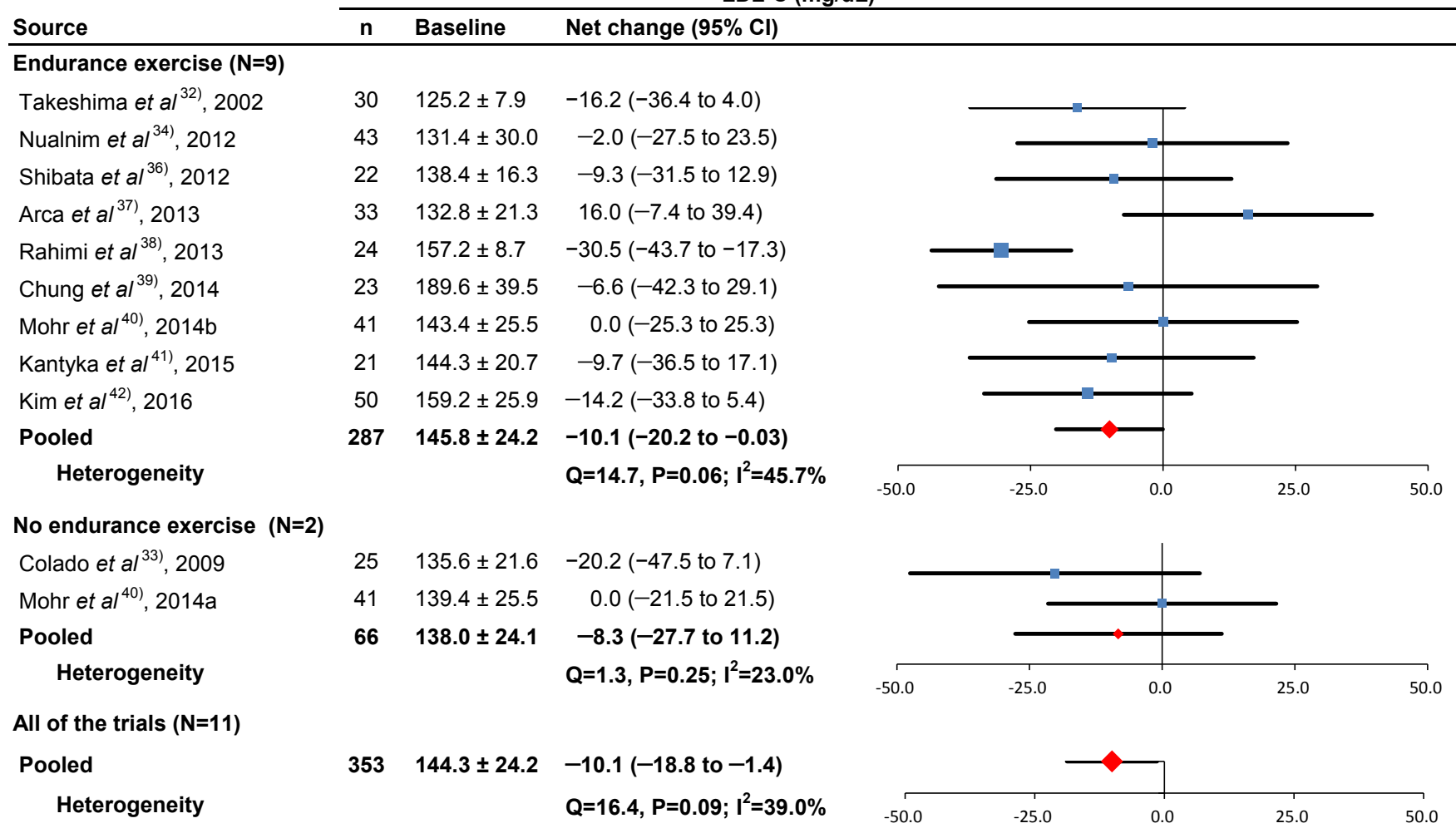

Fig. 3. Baseline LDL-C and forest plot for the net changes in LDL-C. Each trial is represented with black squares (net change) and widths $(95 \% \mathrm{CI})$; the size of the black squares is in proportion to the weighting by inverse variance in each trial. The pooled net changes are represented by black rhombuses (net change) and widths (95\% CI).

Table 2 shows the results of the subgroup analyses when trials were limited to those involving subjects who performed endurance exercise ${ }^{32,34-39,41,42)}$. When trials

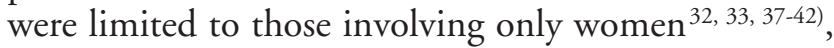
the pooled net changes in HDL-C, LDL-C, and TC improved significantly, but LDL-C contained significant heterogeneity. When trials were limited to those involving subjects with a mean age $<60$ years, the pooled net changes in HDL-C, TC, and TG improved significantly. When trials were limited to those involving subjects with dyslipidemia ${ }^{35,38-42)}$, the pooled net changes in HDLC, LDL-C, TC, and TG improved significantly, but TG contained significant heterogeneity. When trials were limited to those involving subjects without dyslipidemia $^{32-34,36,37)}$, the pooled net changes in HDL-C improved significantly.

BMI was examined as a secondary outcome. The baseline BMI was $26.5 \pm 4.4 \mathrm{~kg} / \mathrm{m}^{2}$ (404 subjects in 11 trials $\left.^{32-35,37-42)}\right)$. The pooled net change in BMI was $-0.2 \mathrm{~kg} / \mathrm{m}^{2}$ (95\% CI, -1.1 to 0.7 for 297 subjects in 9 trials $\left.s^{32-35}, 37,39-41\right)$, and no significant heterogeneity in the BMI was noted $\left(P=0.99\right.$ and $\left.\mathrm{I}^{2}=0.0 \%\right)$.

Supplementary Fig.1-4 show the results of funnel plots in lipids and lipoproteins. When the publica- tion bias was evaluated using the trim and fill method, there were no missing trials for TG. However, there were five missing trials for $\mathrm{HDL}-\mathrm{C}$, five missing trials for LDL-C, and two missing trials for TC. After adjusting for the missing trials, the pooled net changes in HDL-C improved to $7.4 \mathrm{mg} / \mathrm{dL}$ (95\% CI, 3.1 to 11.8 ), those in LDL-C improved to $-18.9 \mathrm{mg} / \mathrm{dL}$ (95\% CI, -28.3 to -9.5$)$, and those in TC improved to -8.5 $\mathrm{mg} / \mathrm{dL}(95 \% \mathrm{CI},-15.5$ to -1.5$)$. Egger's regression test revealed significant asymmetry of the funnel plots of HDL-C and LDL-C ( $P=0.01$ and $P=0.03$, respectively). In a subgroup analysis where trials were limited to those involving subjects who performed swimming alone, subjects with dyslipidemia, or subjects without dyslipidemia, the funnel plots for HDL-C, LDL-C, TC, and TG were not significantly asymmetrical and the trim and fill method of Duval and Tweedie suggested that there were no missing trials (Supplementary Table 3).

\section{Discussion}

According to previous meta-analyses, regular endurance exercise resulted in pooled net changes in HDL-C of approximately $2 \mathrm{mg} / \mathrm{dL}$, pooled net changes in LDL- 
$\mathrm{TC}(\mathrm{mg} / \mathrm{dL})$

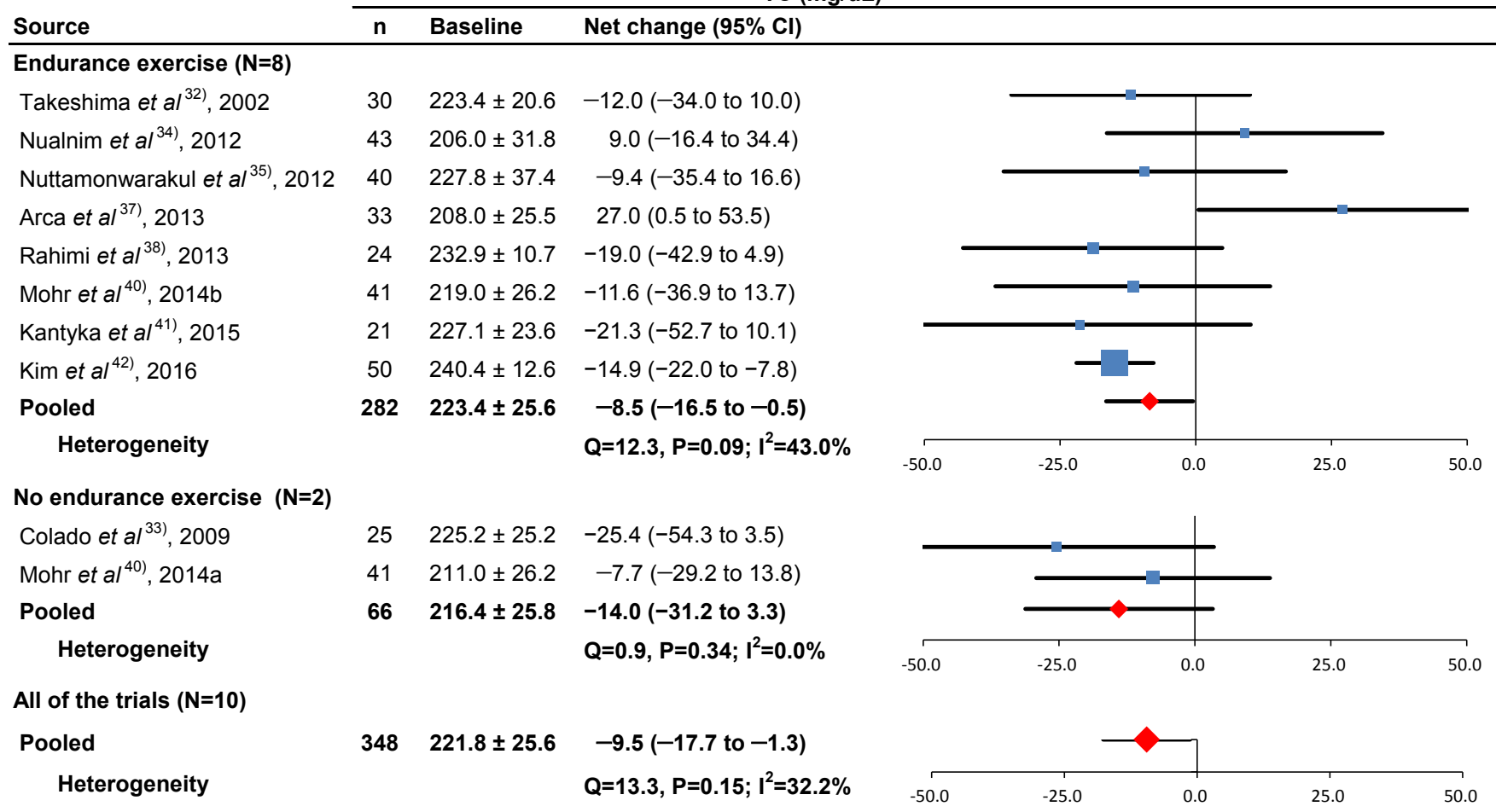

Fig. 4. Baseline TC and forest plot for the net changes in TC. Each trial is represented with black squares (net change) and widths $(95 \% \mathrm{CI})$; the size of the black squares is in proportion to the weighting by inverse variance in each trial. The pooled net changes are represented by black rhombuses (net change) and widths (95\% CI).

$\mathrm{C}$ of approximately $-4 \mathrm{mg} / \mathrm{dL}$, pooled net changes in TC of approximately $-4 \mathrm{mg} / \mathrm{dL}$, and pooled net changes in TG of approximately $-2 \mathrm{mg} / \mathrm{dL}^{10-13)}$. In addition, resistance training resulted in pooled net changes in HDL-C of $0.7 \mathrm{mg} / \mathrm{dL}$, pooled net changes in LDL$\mathrm{C}$ of $-6.1 \mathrm{mg} / \mathrm{dL}$, pooled net changes in TC of -5.5 $\mathrm{mg} / \mathrm{dL}$, and pooled net changes in TG of $-8.1 \mathrm{mg} / \mathrm{dL}$, but HDL-C did not improve significantly ${ }^{14}$. The current meta-analysis evaluated the effects of aquatic exercise on the lipid and lipoprotein levels. The results indicated that exercise resulted in pooled net changes in HDL-C of $3.1 \mathrm{mg} / \mathrm{dL}$, pooled net changes in LDL-C of $-10.1 \mathrm{mg} / \mathrm{dL}$, pooled net changes in TC of -9.5 $\mathrm{mg} / \mathrm{dL}$, and pooled net changes in TG of $-13.7 \mathrm{mg} /$ $\mathrm{dL}$, but the pooled net changes in HDL-C and TG did not improve significantly and contained significant heterogeneity.

When trials were limited to those involving subjects who performed endurance exercise, the HDL-C, LDL-C, and TC levels improved significantly, and subgroup analyses revealed beneficial effects on the lipid and lipoprotein levels in women, subjects with a mean age $<60$ years, and patients with dyslipidemia. In addition, the current meta-analysis revealed greater improvement in lipid and lipoprotein levels than previous meta- analyses $^{10-14)}$, likely because of the influence of baseline dyslipidemia. The baseline LDL-C, TC, and TG levels in the current study were higher than those in previous meta-analyses ${ }^{8-11,14}$. Several meta-analyses have indicated that changes in the lipid and lipoprotein levels are related to the baseline lipid and lipoprotein levels ${ }^{7,8)}$. However, the current study showed that HDL-C improved significantly in trials involving endurance exercise and subjects without dyslipidemia. Thus, aquatic endurance exercise is expected to increase the HDL-C levels, regardless of whether a subject has dyslipidemia or not. In addition, the current study showed that the HDL-C levels improved significantly when trials were limited to those involving an intervention duration $\geq 12$ weeks. Previous meta-analyses have similarly suggested that the exercise time or volume might be associated with the effects of exercise on the lipid and lipoprotein levels $\mathrm{s}^{7,8,13)}$. For example, a meta-analysis reported that the HDL-C levels increased by approximately $1.4 \mathrm{mg} /$ $\mathrm{dL}$ for every $10 \mathrm{~min}$ an exercise session was prolonged ${ }^{13}$. The current meta-analysis involved trials lasting a minimum of 30 min per session, but previous meta-analyses included trials of $<30$ min per session ${ }^{11-13)}$.

The mechanisms by which exercise improved the lipid and lipoprotein levels are still unclear. However, 
$\mathrm{TG}(\mathrm{mg} / \mathrm{dL})$

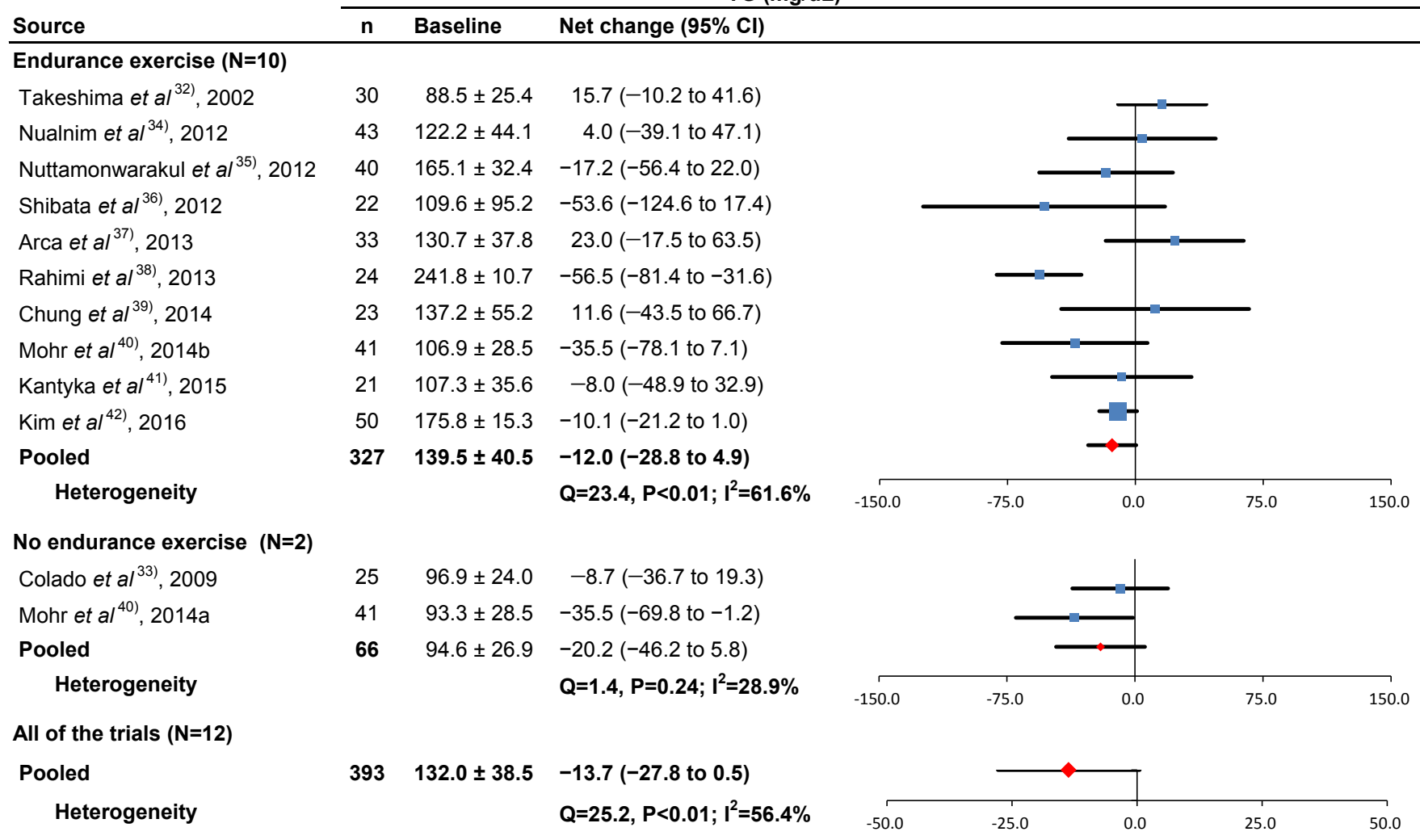

Fig. 5. Baseline TG and forest plot for the net changes in TG. Each trial is represented with black squares (net change) and widths ( $95 \% \mathrm{CI}$ ); the size of the black squares is in proportion to the weighting by inverse variance in each trial. The pooled net changes are represented by black rhombuses (net change) and widths (95\% CI).

given that adipocytokines are considered to cause dyslipidemia ${ }^{43)}$, improvements in lipid and lipoprotein metabolism are presumably related to changes in the adipocytokine levels. A large randomized controlled trial reported that both HDL-C and adiponectin levels increased as a result of lifestyle management and that changes in HDL-C levels were associated with changes in adiponectin levels ${ }^{44)}$. A recent meta-analysis also indicated that endurance exercise reduced the serum leptin levels and increased the adiponectin levels ${ }^{45}$, so endurance exercise may alleviate dyslipidemia via changes in adipocytokine levels.

A meta-analysis suggested that exercise therapy was as effective at preventing cardiovascular disease as drug therapy ${ }^{46}$. Because dyslipidemia is a risk factor for cardiovascular disease ${ }^{1-3)}$ and regular exercise improves the lipid and lipoprotein levels ${ }^{10-16)}$, improved lipid and lipoprotein levels may prevent cardiovascular disease. The mechanism by which exercise prevents cardiovascular disease is thought to be by improving the vascular function. A meta-analysis reported that endurance exercise on land significantly improved the pulse wave velocity ${ }^{47)}$. A cross-sectional study indicated that pulse wave velocity was associated with the HDL-C, TC, and TG levels ${ }^{48)}$. In addition, a controlled clinical trial involving regular aquatic exercise indicated that the percentage change in LDL-C or TC during intervention was related to the percentage change in pulse wave velocity during intervention ${ }^{49)}$. A randomized controlled trial included in the current meta-analysis examined the related vascular function and indicated that swimming training significantly increased the carotid artery compliance ${ }^{34}$. . However, that study found that the lipid and lipoprotein levels did not change significantly from the baseline to after intervention. Because there is little evidence indicating the mechanism by which regular aquatic exercise affects the relationship between the vascular function and lipid or lipoprotein levels, this mechanism is a topic for future study.

The current meta-analysis had several limitations. First, this meta-analysis has a small sample of only 393 subjects, and most were older and/or female. In addition, publication bias was suspected of affecting the net changes in HDL-C, LDL-C, and TC. Once these influences were taken into account and adjusted for, the pooled net changes in HDL-C and LDL-C improved drastically. When trials were limited to those involving women or subjects $\geq 60$ years of age, there were no 
Table 2. Baseline, net changes, and subgroup analyses when trials are limited to aquatic endurance exercise

\begin{tabular}{|c|c|c|c|c|c|}
\hline $\begin{array}{l}\text { Variable } \\
\text { (category) }\end{array}$ & Trials & $\begin{array}{l}\text { Baseline, } \\
\text { mg/dL }\end{array}$ & $\begin{array}{c}\text { Net change, } \\
\mathrm{mg} / \mathrm{dL}\end{array}$ & Q & $\mathrm{I}^{2} \%$ \\
\hline \multicolumn{6}{|l|}{ HDL-C } \\
\hline Women only & $7(222)$ & $48.9 \pm 11.1$ & $5.0(0.6$ to 9.4$)$ & 9.7 & 38.2 \\
\hline Women and men & $2(65)$ & $59.8 \pm 12.2$ & $1.3(-7.0$ to 9.6$)$ & 0.4 & 0.0 \\
\hline Mean age $<60$ years & $3(86)$ & $51.2 \pm 11.1$ & $8.4(3.7$ to 13.1$)$ & 0.9 & 0.0 \\
\hline Mean age $\geq 60$ years & $6(201)$ & $51.5 \pm 11.4$ & $2.2(-2.9$ to 7.4$)$ & 7.7 & 35.3 \\
\hline Intervention duration $\geq 8$ weeks & $8(263)$ & $53.0 \pm 11.8$ & $3.4(-0.5$ to 7.4$)$ & 8.3 & 15.8 \\
\hline Intervention duration $\geq 12$ weeks & $6(218)$ & $51.8 \pm 11.6$ & $5.5(1.6$ to 9.4$)$ & 3.5 & 0.0 \\
\hline Dyslipidemia & $4(118)$ & $50.8 \pm 11.5$ & $6.4(2.0$ to 10.8$)$ & 6.4 & 53.0 \\
\hline No dyslipidemia & $5(169)$ & $51.7 \pm 11.2$ & $4.4(0.01$ to 8.8$)$ & 4.3 & 8.2 \\
\hline \multicolumn{6}{|l|}{ LDL-C } \\
\hline Women only & $7(222)$ & $149.3 \pm 23.6$ & $-12.3(-23.6$ to -1.0$)$ & $13.7^{*}$ & 56.3 \\
\hline Women and men & $2(65)$ & $133.8 \pm 26.2$ & $-6.1(-22.9$ to 10.6$)$ & 0.2 & 0.0 \\
\hline Mean age $<60$ years & $3(86)$ & $147.5 \pm 20.9$ & $-16.0(-36.0$ to 4.1$)$ & 5.3 & 62.2 \\
\hline Mean age $\geq 60$ years & $6(201)$ & $145.0 \pm 25.5$ & $-6.6(-16.2$ to 3.0$)$ & 5.2 & 3.9 \\
\hline Intervention duration $\geq 8$ weeks & $8(263)$ & $144.7 \pm 25.2$ & $-6.2(-14.6$ to 2.2$)$ & 5.5 & 0.0 \\
\hline Intervention duration $\geq 12$ weeks & $6(218)$ & $140.6 \pm 23.9$ & $-5.5(-15.3$ to 4.3$)$ & 5.4 & 7.7 \\
\hline Dyslipidemia & $4(118)$ & $156.3 \pm 26.0$ & $-17.3(-31.7$ to -2.9$)$ & 5.9 & 49.3 \\
\hline No dyslipidemia & $5(169)$ & $139.3 \pm 23.1$ & $-6.3(-17.5$ to 4.9$)$ & 5.2 & 23.1 \\
\hline \multicolumn{6}{|l|}{ TC } \\
\hline Women only & $6(199)$ & $225.7 \pm 20.6$ & $-9.9(-17.8$ to -2.0$)$ & 9.5 & 47.8 \\
\hline Women and men & $1(43)$ & $206.0 \pm 31.8$ & $9.0(-16.4$ to 34.4$)$ & 0.0 & 0.0 \\
\hline Mean age $<60$ years & $3(86)$ & $224.8 \pm 22.2$ & $-16.9(-32.1$ to -1.7$)$ & 0.2 & 0.0 \\
\hline Mean age $\geq 60$ years & $5(196)$ & $222.2 \pm 26.9$ & $-2.6(-17.5$ to 12.4$)$ & $11.5^{*}$ & 65.1 \\
\hline Intervention duration $\geq 8$ weeks (or $\geq 12$ weeks) & $7(258)$ & $222.1 \pm 26.5$ & $-6.2(-17.5$ to 5.0$)$ & 11.9 & 49.0 \\
\hline Dyslipidemia & $4(135)$ & $225.8 \pm 28.0$ & $-15.0(-28.1$ to -1.8$)$ & 0.5 & 0.0 \\
\hline No dyslipidemia & $4(147)$ & $220.8 \pm 23.4$ & $-0.4(-19.0$ to 18.2$)$ & $11.5^{*}$ & 73.8 \\
\hline \multicolumn{6}{|l|}{ TG } \\
\hline Women only & $7(222)$ & $141.2 \pm 30.8$ & $-10.4(-31.5$ to 10.6$)$ & $21.5^{*}$ & 72.1 \\
\hline Women and men & $2(65)$ & $118.0 \pm 66.0$ & $-17.6(-72.3$ to 37.1$)$ & 1.8 & 45.9 \\
\hline Mean age $<60$ years & $3(84)$ & $144.6 \pm 27.0$ & $-36.9(-66.0$ to -7.8$)$ & 4.0 & 50.6 \\
\hline Mean age $\geq 60$ years & $7(241)$ & $137.7 \pm 44.3$ & $-1.9(-15.4$ to 11.6$)$ & 7.8 & 22.9 \\
\hline Intervention duration $\geq 8$ weeks & $9(303)$ & $131.4 \pm 41.9$ & $-5.0(-16.8$ to 6.8$)$ & 9.7 & 17.2 \\
\hline Intervention duration $\geq 12$ weeks & $7(258)$ & $132.8 \pm 32.0$ & $-4.4(-16.7$ to 7.9$)$ & 7.6 & 20.6 \\
\hline Dyslipidemia & $5(158)$ & $149.0 \pm 34.2$ & $-26.3(-50.9$ to -1.7$)$ & 8.0 & 50.0 \\
\hline No dyslipidemia & $5(169)$ & $131.6 \pm 45.0$ & $0.4(-17.8$ to 18.5$)$ & 7.1 & 43.4 \\
\hline
\end{tabular}

CI: confidence intervals; HDL-C: high-density lipoprotein cholesterol; LDL-C: low-density lipoprotein cholesterol; TC: total cholesterol; TG: triglyceride.

Trials are expressed as the number of trials (number of subjects).

Baseline lipids and lipoproteins are expressed as the mean \pm SD.

Trials with a mean HDL-C $<40 \mathrm{mg} / \mathrm{dL}$, mean LDL-C $\geq 140 \mathrm{mg} / \mathrm{dL}$, or mean TG $\geq 150 \mathrm{mg} / \mathrm{dL}$ of subjects were designated as having dyslipidemic subjects.

Net changes in lipids and lipoproteins are expressed as pooled net change $(95 \% \mathrm{CI})$.

* Significant heterogeneity $(P<0.05)$.

signs of publication bias with regard to LDL-C, TC, and TG. Therefore, new randomized controlled trials - particularly those involving men and subjects $<60$ years of age - should be included in a future meta- analysis. Second, this meta-analysis did not perform a subgroup analysis of the effects of baseline levels of lipids and lipoproteins based on the guidelines of the American College of Cardiology and the American 
Heart Association ${ }^{2)}$. According to these guidelines, statin therapy is indicated when a patient's LDL-C level is $\geq 190 \mathrm{mg} / \mathrm{dL}(70-189 \mathrm{mg} / \mathrm{dL}$ if a patient has diabetes), a patient has atherosclerotic cardiovascular disease, or a patient has a 10-year risk of developing atherosclerotic cardiovascular disease $\geq 7.5 \%{ }^{2}$. The current meta-analysis suggested that not all the trial subjects met these criteria based on their mean LDL-C levels at the baseline, and patients with cardiovascular disease and those undergoing cardiac rehabilitation were excluded as subjects. Therefore, the current meta-analysis did not analyze individuals who needed to take statins. A cohort study reported that statin therapy and increased fitness were independently associated with mortality ${ }^{50)}$. Thus, the combination of statin therapy and increased physical activity is a crucial way of improving the health in patients with dyslipidemia. However, there is little evidence regarding the efficacy of the combination of exercise and statin therapy, so future studies should evaluate the effects of exercise on the lipid and lipoprotein levels (in individuals at risk of developing dyslipidemia).

\section{Conclusion}

The results of a meta-analysis indicated that aquatic endurance exercise improved the lipid and lipoprotein levels. This form of exercise particularly benefited women, the middle-aged, and patients with dyslipidemia. However, the current meta-analysis had a small sample size, so additional trials must be included in the future in order to confirm the effects of regular aquatic exercise on lipid and lipoprotein levels.

\section{Funding}

This research received no specific grant from any funding agency in the public, commercial, or not-forprofit sectors.

\section{Acknowledgment}

A special thanks to the staff of Osaka University of Health and Sports Sciences Library for collecting literature for our analysis.

\section{List of Abbreviations}

HDL-C: high-density lipoprotein cholesterol

LDL-C: low-density lipoprotein cholesterol

TC: total cholesterol

TG: triglyceride

PRISMA: Preferred Reporting Items for Systematic

Reviews and Meta-analyses
SD: standard deviation

BMI: body mass index

PEDro: Physiotherapy Evidence Database

$\mathrm{CI}$ : confidence intervals

\section{Conflicts of Interests}

None.

\section{References}

1) Madsen CM, Varbo A, and Nordestgaard BG: Extreme high high-density lipoprotein cholesterol is paradoxically associated with high mortality in men and women: two prospective cohort studies. Eur Heart J, 2017; 38: 24782486

2) Stone NJ, Robinson JG, Lichtenstein AH, Bairey Merz $\mathrm{CN}$, Blum CB, Eckel RH, Goldberg AC, Gordon D, Levy D, Lloyd-Jones DM, McBride P, Schwartz JS, Shero ST, Smith SC Jr, Watson K, Wilson PW, Eddleman KM, Jarrett NM, LaBresh K, Nevo L, Wnek J, Anderson JL, Halperin JL, Albert NM, Bozkurt B, Brindis RG, Curtis LH, DeMets D, Hochman JS, Kovacs RJ, Ohman EM, Pressler SJ, Sellke FW, Shen WK, Smith SC Jr, Tomaselli GF, and American College of Cardiology/American Heart Association Task Force on Practice Guidelines: 2013 ACC/ AHA guideline on the treatment of blood cholesterol to reduce atherosclerotic cardiovascular risk in adults: a report of the American College of Cardiology/American Heart Association Task Force on Practice Guidelines. Circulation, 2014; 129: S1-45

3) Scandinavian Simvastatin Survival Study Group: Randomised trial of cholesterol lowering in 4444 patients with coronary heart disease: the Scandinavian Simvastatin Survival Study (4S). Lancet, 1994; 344: 1383-1389

4) Yu-Poth $S$, Zhao G, Etherton T, Naglak M, Jonnalagadda $S$, and, Kris-Etherton PM: Effects of the National Cholesterol Education Program's Step I and Step II dietary intervention programs on cardiovascular disease risk factors: a meta-analysis. Am J Clin Nutr, 1999; 69: 632-646

5) Mensink RP, Zock PL, Kester AD, and Katan MB: Effects of dietary fatty acids and carbohydrates on the ratio of serum total to HDL cholesterol and on serum lipids and apolipoproteins: a meta-analysis of 60 controlled trials. Am J Clin Nutr, 2003; 77: 1146-1155

6) Uauy R, Aro A, Clarke R, Ghafoorunissa R, L'Abbé MR, Mozaffarian D, Skeaff CM, Stender S, and Tavella M: WHO Scientific Update on trans fatty acids: summary and conclusions. Eur J Clin Nutr, 2009; 63: S68-S75

7) Leon AS, Sanchez OA: Response of blood lipids to exercise training alone or combined with dietary intervention. Med Sci Sports Exerc, 2001; 33: S502-515

8) Kelley GA, Kelley KS, Roberts S, and Haskell W: Combined effects of aerobic exercise and diet on lipids and lipoproteins in overweight and obese adults: a meta-analysis. J Obes, 2012; 2012: 985902

9) Kelley GA, Kelley KS, Roberts S, and Haskell W: Comparison of aerobic exercise, diet or both on lipids and lipoproteins in adults: a meta-analysis of randomized con- 
trolled trials. Clin Nutr, 2012; 31: 156-167

10) Kelley GA, Kelley KS, and Tran ZV: Walking, lipids, and lipoproteins: a meta-analysis of randomized controlled trials. Prev Med, 2004; 38: 651-661

11) Kelley GA, Kelley KS, and Tran ZV: Aerobic exercise and lipids and lipoproteins in women: a meta-analysis of randomized controlled trials. J Womens Health (Larchmt), 2004; 13: 1148-1164

12) Kelley GA, Kelley KS, and Tran ZV: Exercise, lipids, and lipoproteins in older adults: a meta-analysis. Prev Cardiol, 2005; 8: 206-214

13) Kodama S, Tanaka S, Saito K, Shu M, Sone Y, Onitake F, Suzuki E, Shimano H, Yamamoto S, Kondo K, Ohashi Y, Yamada N, and Sone H: Effect of aerobic exercise training on serum levels of high-density lipoprotein cholesterol: a meta-analysis. Arch Intern Med, 2007; 167: 999-1008

14) Kelley GA and Kelley KS: Impact of progressive resistance training on lipids and lipoproteins in adults: a meta-analysis of randomized controlled trials. Prev Med, 2009; 48: 9-19

15) Pan XH, Mahemuti A, Zhang XH, Wang YP, Hu P, Jiang JB, Xiang MX, Liu G, and Wang JA: Effect of Tai Chi exercise on blood lipid profiles: a meta-analysis of randomized controlled trials. J Zhejiang Univ Sci B, 2016; 17: 640-648

16) Chu P, Gotink RA, Yeh GY, Goldie SJ, and Hunink MG: The effectiveness of yoga in modifying risk factors for cardiovascular disease and metabolic syndrome: A systematic review and meta-analysis of randomized controlled trials. Eur J Prev Cardiol, 2016; 23: 291-307

17) Denning WM, Bressel E, Dolny D, Bressel M, and Seeley MK: A review of biophysical differences between aquatic and land-based exercise. Int J Aquatic Res Educ, 2012; 6: 46-67

18) Torres-Ronda L and Del Alcázar XS: The properties of water and their applications for training. J Hum Kinet, 2014; 44: 237-248

19) Igarashi $Y$ and Nogami Y: The effect of regular aquatic exercise on blood pressure: A meta-analysis of randomized controlled trials. Eur J Prev Cardiol, 2018; 25: 190-199

20) Uthman OA, van der Windt DA, Jordan JL, Dziedzic KS, Healey EL, Peat GM, and Foster NE: Exercise for lower limb osteoarthritis: systematic review incorporating trial sequential analysis and network meta-analysis. BMJ, 2013; 347: f5555

21) Ainsworth BE, Haskell WL, Herrmann SD, Meckes N, Bassett DR Jr, Tudor-Locke C, Greer JL, Vezina J, WhittGlover MC, and Leon AS: 2011 Compendium of Physical Activities: a second update of codes and MET values. Med Sci Sports Exerc, 2011; 43: 1575-1581

22) Shamseer L, Moher D, Clarke M, Ghersi D, Liberati A, Petticrew M, Shekelle P, Stewart LA, and PRISMA-P Group: Preferred reporting items for systematic review and metaanalysis protocols (PRISMA-P) 2015: elaboration and explanation. BMJ, 2015; 349: g7647

23) Cornelissen VA and Smart NA: Exercise training for blood pressure: a systematic review and meta-analysis. J Am Heart Assoc, 2013; 2: e004473

24) Moseley AM, Herbert RD, Sherrington C, and Maher CG: Evidence for physiotherapy practice: a survey of the Physiotherapy Evidence Database (PEDro). Aust J Physiother,
2002; 48: 43-49

25) DerSimonian R and Laird N: Meta-analysis in clinical trials. Control Clin Trials, 1986; 7: 177-188

26) Follmann D, Elliott P, Suh I, and Cutler J: Variance imputation for overviews of clinical trials with continuous response. J Clin Epidemiol, 1992; 45: 769-773

27) Higgins JP and Thompson SG: Quantifying heterogeneity in a meta-analysis. Stat Med, 2002; 21: 1539-1558

28) Haskell WL, Lee IM, Pate RR, Powell KE, Blair SN, Franklin BA, Macera CA, Heath GW, Thompson PD, and Bauman A; American College of Sports Medicine; American Heart Association: Physical activity and public health: updated recommendation for adults from the American College of Sports Medicine and the American Heart Association. Circulation, 2007; 116: 1081-1093

29) Kinoshita M, Yokote K, Arai H, Iida M, Ishigaki Y, Ishibashi S, Umemoto S, Egusa G, Ohmura H, Okamura T, Kihara S, Koba S, Saito I, Shoji T, Daida H, Tsukamoto K, Deguchi J, Dohi S, Dobashi K, Hamaguchi H, Hara M, Hiro T, Biro S, Fujioka Y, Maruyama C, Miyamoto Y, Murakami Y, Yokode M, Yoshida H, Rakugi H, Wakatsuki A, Yamashita S, and Committee for Epidemiology and Clinical Management of Atherosclerosis: Japan Atherosclerosis Society (JAS) Guidelines for Prevention of Atherosclerotic Cardiovascular Diseases 2017. J Atheroscler Thromb, 2018; 25: 846-984

30) Duval $S$ and Tweedie R: Trim and fill: A simple funnelplot-based method of testing and adjusting for publication bias in meta-analysis. Biometrics, 2000; 56: 455-463

31) Egger M, Davey Smith G, Schneider M, and Minder C: Bias in meta-analysis detected by a simple, graphical test. BMJ, 1997; 315: 629-634

32) Takeshima N, Rogers ME, Watanabe E, Brechue WF, Okada A, Yamada T, Islam MM, and Hayano J: Waterbased exercise improves health-related aspects of fitness in older women. Med Sci Sports Exerc, 2002; 34: 544-551

33) Colado JC, Triplett NT, Tella V, Saucedo P, and Abellán J: Effects of aquatic resistance training on health and fitness in postmenopausal women. Eur J Appl Physiol, 2009; 106: $113-122$

34) Nualnim N, Parkhurst K, Dhindsa M, Tarumi T, Vavrek J, and Tanaka H: Effects of swimming training on blood pressure and vascular function in adults $>50$ years of age. Am J Cardiol, 2012; 109: 1005-1010

35) Nuttamonwarakul A, Amatyakul S, and Suksom D: Twelve weeks of aqua-aerobic exercise improve health-related physical adaptations and glycemic control in elderly patients with type 2 diabetes. J Exerc Physiol Online, 2012; 15: 64-70

36) Shibata Y, Hayasaka S, Ojima T, and Goto Y: Effects of water exercise on physiological and psychological health in the Japanese: Kawane Spa Study. Int SportMed J, 2012; 13: 190-202

37) Arca EA, Martinelli B, Martin LC, Waisberg CB, and Franco RJ: Aquatic exercise is as effective as dry land training to blood pressure reduction in postmenopausal hypertensive women. Physiother Res In, 2014; 19: 93-98

38) Rahimi A, Shabestari MM, Faryadian K, Safaeinejad V, Moazen JS, and Fallah Z: The effect of selecting aerobics exercise program (walking in water and in land) on HDLC, LDL-C, TC and TG in non-athlete menopausal women. 
Eur J Exp Biol, 2013; 3: 463-468

39) Chung PK, Mui R, Zhao YN, and Liu J: Training effects of water Tai Chi on health indicators among Chinese older females in Hong Kong. Int J Phys Educ Sports Health, 2014; 1: 20-24

40) Mohr M, Nordsborg NB, Lindenskov A, Steinholm H, Nielsen HP, Mortensen J, Weihe P, and Krustrup P: Highintensity intermittent swimming improves cardiovascular health status for women with mild hypertension. Biomed Res Int, 2014; 728289

41) Kantyka J, Herman D, Roczniok R, and Kuba L: Effects of aqua aerobics on body composition, body mass, lipid profile, and blood count in middle-aged sedentary women. Hum Movement, 2015; 16: 9-14

42) Kim WC, Choi SL, Kim SW, and Park HR: The effects of aquarobics on blood pressure, heart rate, and lipid profile in older women with hypertension. Indian J Sci Tech, 2016; 9: 1-7

43) Izadi V, Farabad E, and Azadbakht L: Epidemiologic evidence on serum adiponectin level and lipid profile. Int J Prev Med, 2013; 4: 133-140

44) Belalcazar LM, Lang W, Haffner SM, Hoogeveen RC, PiSunyer FX, Schwenke DC, Balasubramanyam A, Tracy RP, Kriska AP, Ballantyne CM, and Look AHEAD Research Group: Adiponectin and the mediation of HDL-cholesterol change with improved lifestyle: the Look AHEAD Study. J Lipid Res, 2012; 53: 2726-2733

45) Yu N, Ruan Y, Gao X, and Sun J: Systematic Review and
Meta-Analysis of Randomized, Controlled Trials on the Effect of Exercise on Serum Leptin and Adiponectin in Overweight and Obese Individuals. Horm Metab Res, 2017; 49: $164-173$

46) Naci $\mathrm{H}$ and Ioannidis JP: Comparative effectiveness of exercise and drug interventions on mortality outcomes: metaepidemiological study. BMJ, 2013; 347: f5577

47) Ashor AW, Lara J, Siervo M, Celis-Morales C, and Mathers JC: Effects of exercise modalities on arterial stiffness and wave reflection: a systematic review and meta-analysis of randomized controlled trials. PLoS One, 2014; 9: e110034

48) Tomiyama H, Yamashina A, Arai T, Hirose K, Koji Y, Chikamori T, Hori S, Yamamoto Y, Doba N, and Hinohara S: Influences of age and gender on results of noninvasive brachial-ankle pulse wave velocity measurement--a survey of 12517 subjects. Atherosclerosis, 2003; 166: 303309

49) Kawasaki T, Sullivan CV, Ozoe N, Higaki H, and Kawasaki J: A long-term, comprehensive exercise program that incorporates a variety of physical activities improved the blood pressure, lipid and glucose metabolism, arterial stiffness, and balance of middle-aged and elderly Japanese. Hypertens Res, 2011; 34: 1059-1066

50) Kokkinos PF, Faselis C, Myers J, Panagiotakos D, and Doumas M: Interactive effects of fitness and statin treatment on mortality risk in veterans with dyslipidaemia: a cohort study. Lancet, 2013; 381: 394-399 
Supplementary Table 1. Study quality based on PEDro

\begin{tabular}{|c|c|c|c|c|c|c|c|c|c|c|}
\hline Study name & \multicolumn{9}{|c|}{ Items } & Total Score \\
\hline Takeshima et al ${ }^{32)}, 2002$ & Yes & No & Yes & Yes & No & No & Yes & Yes & Yes & 5 \\
\hline Colado et al ${ }^{33)}, 2009$ & Yes & No & Yes & Yes & No & No & Yes & Yes & Yes & 5 \\
\hline Nualnim et al ${ }^{34)}, 2012$ & Yes & No & Yes & Yes & Yes & Yes & No & Yes & Yes & 7 \\
\hline Nuttamonwarakul et al ${ }^{35)}, 2012$ & Yes & No & Yes & Yes & No & No & Yes & Yes & Yes & 5 \\
\hline Rahimi et al ${ }^{38)}, 2013$ & Yes & No & No & Yes & No & No & No & Yes & Yes & 3 \\
\hline Chung et al ${ }^{39)}, 2014$ & Yes & No & Yes & Yes & No & No & Yes & Yes & Yes & 5 \\
\hline Mohr et al ${ }^{40)}, 2014 \mathrm{a}$ & Yes & No & Yes & Yes & No & No & Yes & Yes & Yes & 5 \\
\hline Mohr et al ${ }^{40)}, 2014 \mathrm{~b}$ & Yes & No & Yes & Yes & No & No & Yes & Yes & Yes & 5 \\
\hline Kantyka et al ${ }^{41)}, 2015$ & Yes & No & Yes & Yes & No & No & Yes & Yes & Yes & 5 \\
\hline
\end{tabular}

1: Random allocated to groups, 2: Concealed allocation, 3: Groups that were similar at baseline, 4: The blinding of assessors, 5: Outcome measures that were obtained from more than $85 \%$ of subjects, 6: Intention to treat analysis, 7: Between-group statistical comparisons, 8: Provided both point measures and measures of variability, 9: Eligibility criteria (note: eligibility criteria does not contribute to total score).

Supplementary Table 2. Baseline, net changes, and subgroup analyses when RCTs limited involving swimming or no swimming

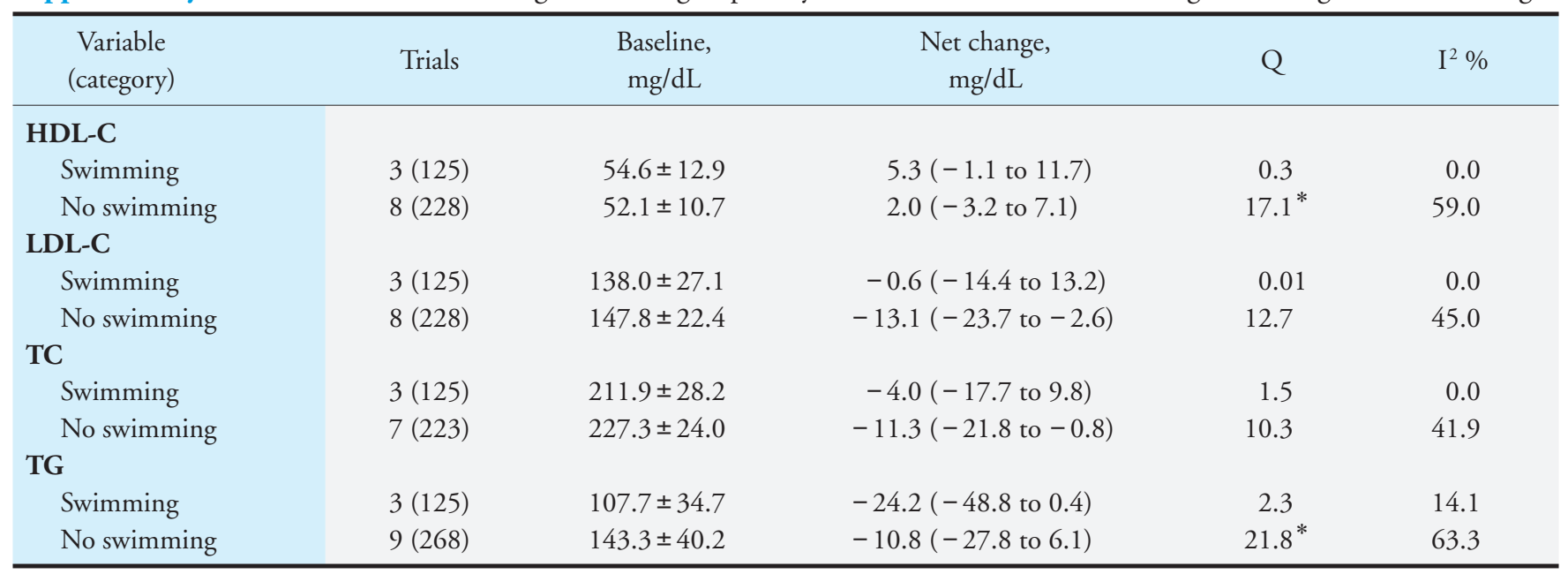

CI: confidence intervals; HDL-C: high-density lipoprotein cholesterol; LDL-C: low-density lipoprotein cholesterol; TC: total cholesterol; TG: triglyceride.

Trials are expressed number of trials (number of subjects)

Baseline lipids and lipoproteins are expressed as mean \pm SD

Net changes in lipids and lipoproteins are expressed as pooled net change $(95 \% \mathrm{CI})$

* Significant heterogeneity $(P<0.05)$ 


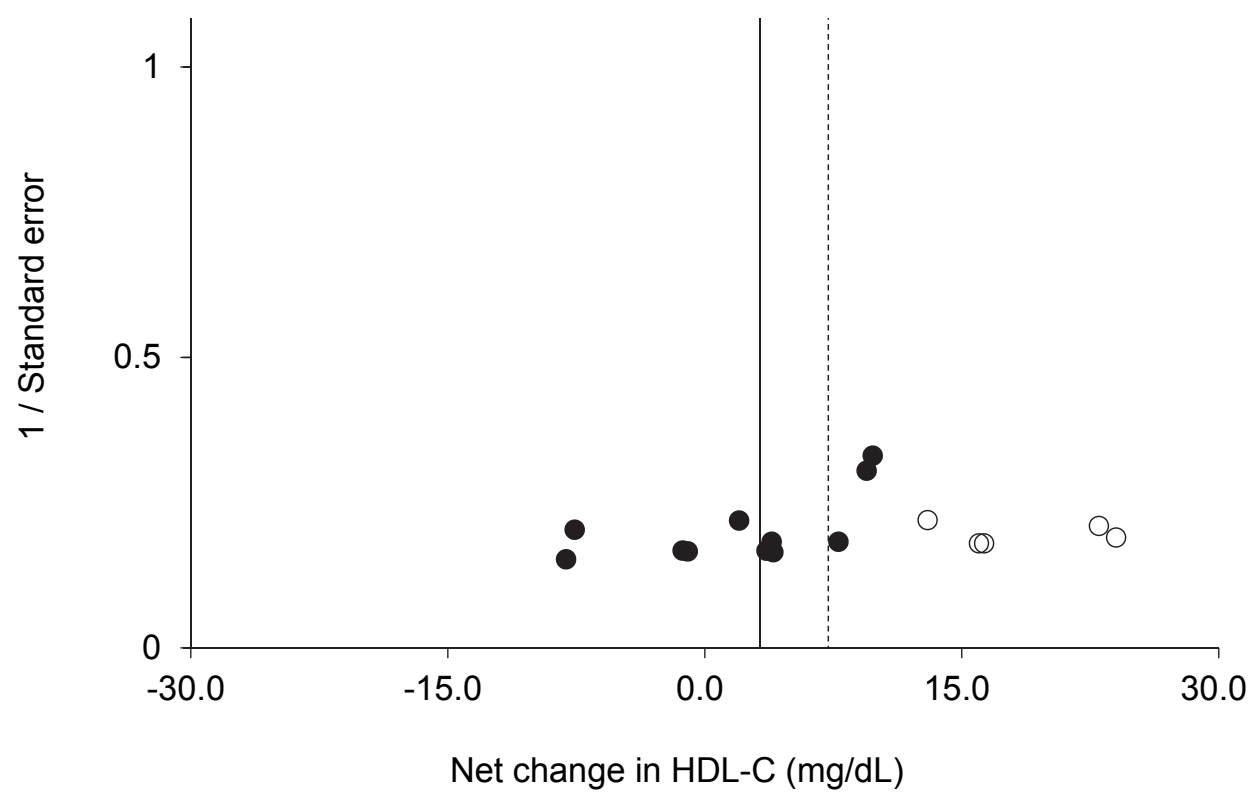

Supplementary Fig. 1. Funnel plot of HDL-C for each trial. Egger's regression test indicated that the funnel plot had significant asymmetry. A vertical line indicates the pooled net change in HDL-C $(3.1 \mathrm{mg} / \mathrm{dL})$. The trim and fill method of Duval and Tweedie suggested that there were five missing trials (white circles). A dotted vertical line indicates the pooled net change in HDL-C after adjusting for the missing trials $(7.4 \mathrm{mg} / \mathrm{dL})$.

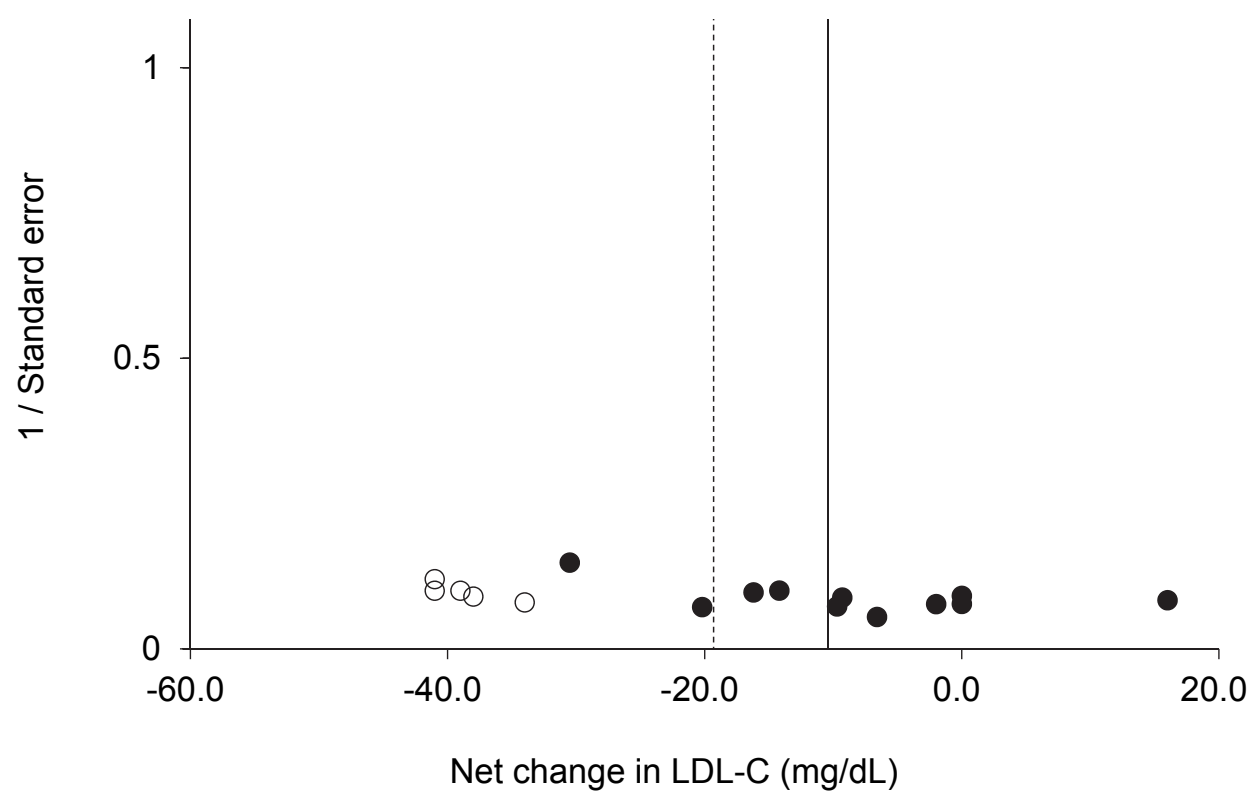

Supplementary Fig. 2. Funnel plot for LDL-C for each trial. Egger's regression test indicated that the funnel plot had significant asymmetry. A vertical line indicates the pooled net change in LDL-C $(-10.1 \mathrm{mg} / \mathrm{dL})$. The trim and fill method of Duval and Tweedie suggested that there were five missing trials (white circles). A dotted vertical line indicates the pooled net change in LDL-C after adjusting for the missing trials $(-18.9 \mathrm{mg} / \mathrm{dL})$. 


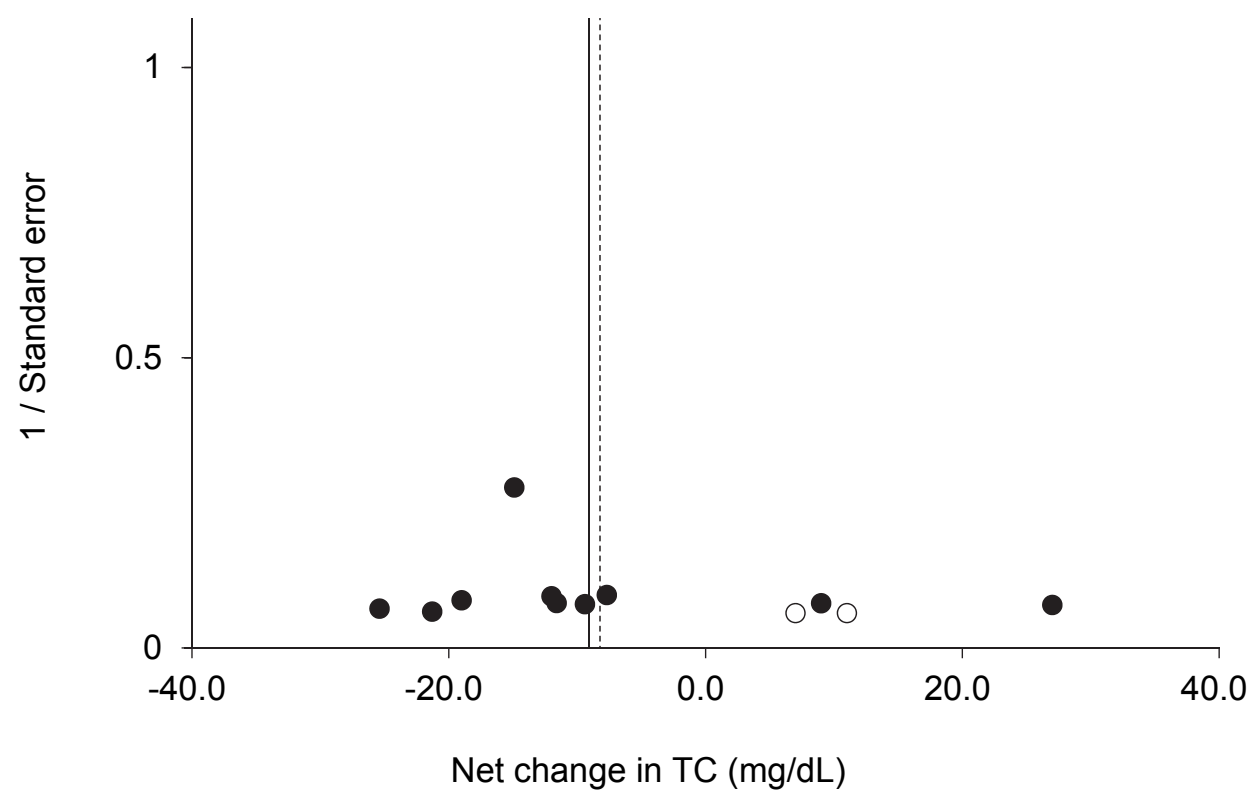

Supplementary Fig. 3. Funnel plot for TC for each trial. Egger's regression test indicated that the funnel plot had significant asymmetry. A vertical line indicates the pooled net change in TC $(-9.5 \mathrm{mg} / \mathrm{dL})$. The trim and fill method of Duval and Tweedie suggested that there were two missing trials (white circles). A dotted vertical line indicates the pooled net change in TC after adjusting for the missing trials $(-8.5 \mathrm{mg} / \mathrm{dL})$.

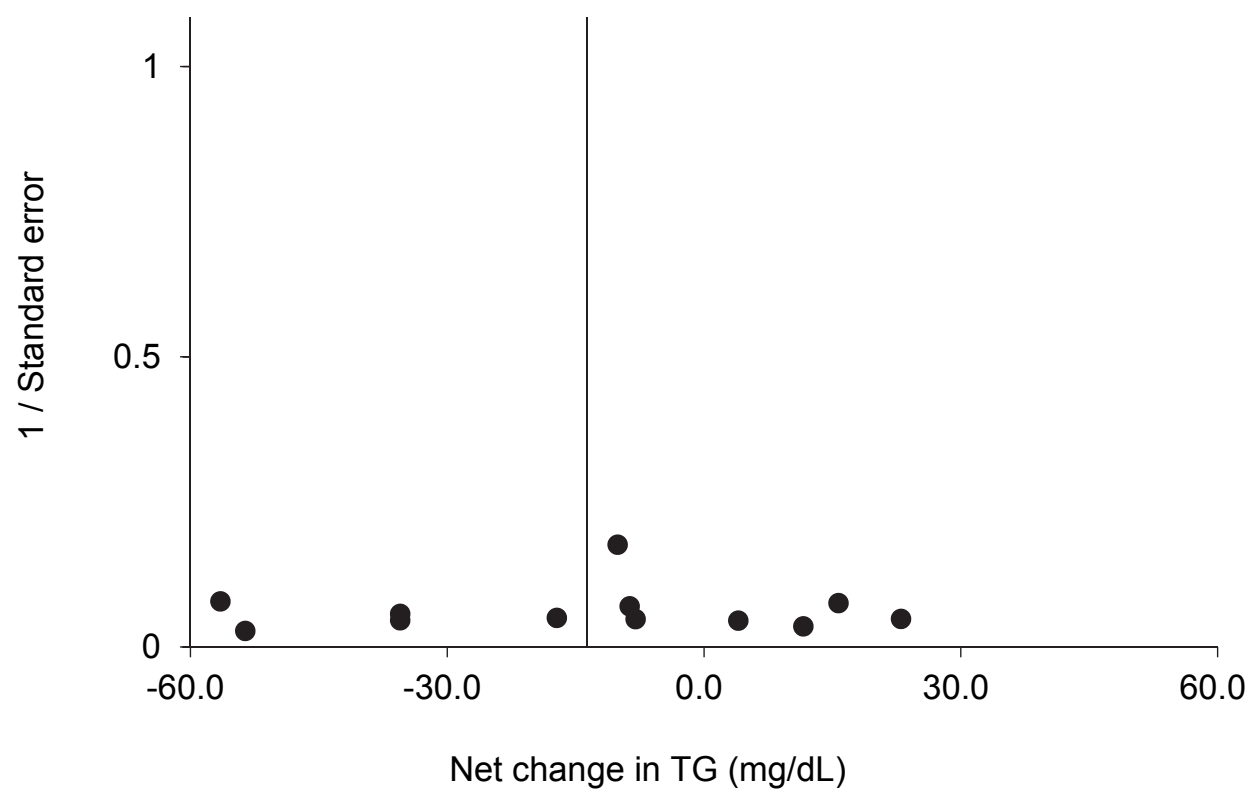

Supplementary Fig. 4. Funnel plot of TG for each trial. Egger's regression test indicated that the funnel plot did not have significant asymmetry. A vertical line indicated the pooled net change in TG $(-13.7 \mathrm{mg} / \mathrm{dL})$. The trim and fill method of Duval and Tweedie did not suggest that there were any missing trials. 
Supplementary Table 3. Publication bias

\begin{tabular}{|c|c|c|c|c|c|c|}
\hline \multirow[b]{2}{*}{ Variable (category) } & \multirow[b]{2}{*}{ Trials } & \multirow{2}{*}{$\begin{array}{l}\text { Net change, } \\
\mathrm{mg} / \mathrm{dL}\end{array}$} & \multicolumn{2}{|c|}{ Trim and fill method } & \multicolumn{2}{|c|}{ Regression test } \\
\hline & & & $\begin{array}{c}\text { Missing } \\
\text { trials }\end{array}$ & $\begin{array}{l}\text { Adjusted net change, } \\
\mathrm{mg} / \mathrm{dL}\end{array}$ & Interception & $P$ \\
\hline \multicolumn{7}{|l|}{ HDL-C } \\
\hline All trials & 11 & $3.1(-0.8$ to 6.9$)$ & 5 & $7.4(3.1$ to 11.8$)$ & -3.3 & 0.01 \\
\hline Endurance exercise & 9 & $4.6(0.8$ to 8.3$)$ & 4 & $8.0(3.7$ to 12.2$)$ & -3.2 & 0.01 \\
\hline No endurance exercise & 2 & $-2.1(-13.4$ to 9.2$)$ & N/A & & N/A & \\
\hline Swimming & 3 & $5.3(-1.1$ to 11.7$)$ & 0 & & -3.1 & 0.70 \\
\hline No swimming & 8 & $2.0(-3.2$ to 7.1$)$ & 4 & $7.3(1.7$ to 12.8$)$ & -4.3 & 0.01 \\
\hline Women only & 7 & $5.0(0.6$ to 9.4$)$ & 2 & $7.2(2.3$ to 12.2$)$ & -3.4 & 0.02 \\
\hline Women and men & 2 & $1.3(-7.0$ to 9.6$)$ & N/A & & N/A & \\
\hline Mean age $<60$ years & 3 & $8.4(3.7$ to 13.1$)$ & 2 & $9.8(5.7$ to 13.9$)$ & -1.6 & 0.30 \\
\hline Mean age $\geq 60$ years & 6 & $2.2(-2.9$ to 7.4$)$ & 3 & $6.1(0.7$ to 11.5$)$ & -3.9 & 0.02 \\
\hline Intervention duration $\geq 8$ weeks & 8 & $3.4(-0.5$ to 7.4$)$ & 3 & $6.0(1.6$ to 10.4$)$ & -3.3 & 0.03 \\
\hline Intervention duration $\geq 12$ weeks & 6 & $5.5(1.6$ to 9.4$)$ & 3 & $8.0(4.3$ to 11.7$)$ & -2.3 & 0.11 \\
\hline Dyslipidemia & 4 & $6.4(2.0$ to 10.8$)$ & 0 & & -3.1 & 0.20 \\
\hline No dyslipidemia & 5 & $4.4(0.01$ to 8.8$)$ & 2 & $6.2(1.6$ to 10.7$)$ & -3.2 & 0.04 \\
\hline \multicolumn{7}{|l|}{ LDL-C } \\
\hline All trials & 11 & $-10.1(-18.8$ to -1.4$)$ & 5 & $-18.9(-28.3$ to -9.5$)$ & 3.2 & 0.03 \\
\hline Endurance exercise & 9 & $-10.1(-20.2$ to -0.03$)$ & 4 & $-18.4(-28.9$ to -7.9$)$ & 3.6 & 0.02 \\
\hline No endurance exercise & 2 & $-8.3(-27.7$ to 11.2$)$ & N/A & & N/A & \\
\hline Swimming & 3 & $-0.6(-14.4$ to 13.2$)$ & 0 & & -3.3 & 0.62 \\
\hline No swimming & 8 & $-13.1(-23.7$ to -2.6$)$ & 4 & $-22.1(-33.3$ to -11.0$)$ & 2.9 & 0.09 \\
\hline Women only & 7 & $-12.3(-23.6$ to -1.0$)$ & 3 & $-20.0(-33.3$ to -6.7$)$ & 3.6 & 0.06 \\
\hline Women and men & 2 & $-6.1(-22.9$ to 10.6$)$ & N/A & & N/A & \\
\hline Mean age $<60$ years & 3 & $-16.0(-36.0$ to 4.1$)$ & 2 & $-30.5(-50.6$ to -10.5$)$ & 3.9 & 0.19 \\
\hline Mean age $\geq 60$ years & 6 & $-6.6(-16.2$ to 3.0$)$ & 1 & $-3.9(-13.1$ to 5.4$)$ & 1.8 & 0.50 \\
\hline Intervention duration $\geq 8$ weeks & 8 & $-6.2(-14.6$ to 2.2$)$ & 0 & & 1.6 & 0.43 \\
\hline Intervention duration $\geq 12$ weeks & 6 & $-5.5(-15.3$ to 4.3$)$ & 0 & & 4.0 & 0.30 \\
\hline Dyslipidemia & 4 & $-17.3(-31.7$ to -2.9$)$ & 2 & $-23.2(-37.9$ to -8.4$)$ & 2.9 & 0.10 \\
\hline No dyslipidemia & 5 & $-6.3(-17.5$ to 4.9$)$ & 0 & & 7.5 & 0.19 \\
\hline \multicolumn{7}{|l|}{ TC } \\
\hline All trials & 10 & $-9.5(-17.7$ to -1.3$)$ & 2 & $-8.5(-15.5$ to -1.5$)$ & 0.7 & 0.33 \\
\hline Endurance exercise & 8 & $-8.5(-16.5$ to -0.5$)$ & 1 & $-6.8(-13.1$ to -0.5$)$ & 1.0 & 0.27 \\
\hline No endurance exercise & 2 & $-14.0(-31.2$ to 3.3$)$ & N/A & & N/A & \\
\hline Swimming & 3 & $-4.0(-17.7$ to 9.8$)$ & 0 & & 3.3 & 0.75 \\
\hline No swimming & 7 & $-11.3(-21.8$ to -0.8$)$ & 2 & $-8.3(-16.0$ to -0.6$)$ & 0.5 & 0.61 \\
\hline Women only & 6 & $-9.9(-17.8$ to -2.0$)$ & 2 & $-5.9(-16.8$ to 5.0$)$ & 0.8 & 0.49 \\
\hline Women and men & 1 & $9.0(-16.4$ to 34.4$)$ & $\mathrm{N} / \mathrm{A}$ & & N/A & \\
\hline Mean age $<60$ years & 3 & $-16.9(-32.1$ to -1.7$)$ & 0 & & -1.1 & 0.72 \\
\hline Mean age $\geq 60$ years & 5 & $-2.6(-17.5$ to 12.4$)$ & 0 & & 2.0 & 0.15 \\
\hline $\begin{array}{l}\text { Intervention duration } \geq 8 \text { weeks } \\
\text { (or } \geq 12 \text { weeks) }\end{array}$ & 7 & $-6.2(-17.5$ to 5.0$)$ & 0 & & 1.2 & 0.22 \\
\hline Dyslipidemia & 4 & $-15.0(-28.1$ to -1.8$)$ & 1 & $-13.6(-25.7$ to -1.5$)$ & -1.2 & 0.67 \\
\hline No dyslipidemia & 4 & $-0.4(-19.0$ to 18.2$)$ & 0 & & 2.5 & 0.18 \\
\hline
\end{tabular}


(Cont. Supplementary Table 3)

\begin{tabular}{|c|c|c|c|c|c|c|}
\hline Variable (category) & Trials & $\begin{array}{c}\text { Net change, } \\
\text { mg/dL }\end{array}$ & \multicolumn{2}{|c|}{ Trim and fill method } & \multicolumn{2}{|c|}{ Regression test } \\
\hline \multicolumn{7}{|l|}{ TG } \\
\hline All trials & 12 & $-13.7(-27.8$ to 0.5$)$ & 0 & & -0.2 & 0.85 \\
\hline Endurance exercise & 10 & $-12.0(-28.8$ to 4.9$)$ & 0 & & 0.0 & 0.97 \\
\hline Swimming & 3 & $-24.2(-48.8$ to 0.4$)$ & 0 & & 4.8 & 0.60 \\
\hline No swimming & 9 & $-10.8(-27.8$ to 6.1$)$ & 0 & & 0.0 & 0.97 \\
\hline Women only & 7 & $-10.4(-31.5$ to 10.6$)$ & 1 & $-15.1(-35.4$ to 5.2$)$ & 0.2 & 0.88 \\
\hline Women and men & 2 & $-17.6(-72.3$ to 37.1$)$ & N/A & & N/A & \\
\hline Mean age $<60$ years & 3 & $-36.9(-66.0$ to -7.8$)$ & 2 & $-56.5(-86.3$ to -26.7$)$ & 4.0 & 0.34 \\
\hline Dyslipidemia & 5 & $-26.3(-50.9$ to -1.7$)$ & 2 & $-39.5(-63.7$ to -15.3$)$ & -4.3 & 0.03 \\
\hline No dyslipidemia & 5 & $0.4(-17.8$ to 18.5$)$ & 0 & & 0.6 & 0.63 \\
\hline
\end{tabular}

CI: confidence intervals; HDL-C: high-density lipoprotein cholesterol; LDL-C: low-density lipoprotein cholesterol; N/A: not available; TC: total cholesterol; TG: triglyceride.

Net changes in lipids and lipoproteins are expressed as pooled net change $(95 \% \mathrm{CI})$.

Trials with a mean HDL-C $<40 \mathrm{mg} / \mathrm{dL}$, mean LDL-C $\geq 140 \mathrm{mg} / \mathrm{dL}$, or mean TG $\geq 150 \mathrm{mg} / \mathrm{dL}$ of subjects were designated as having dyslipidemia of subjects. 